\title{
TILLING - a shortcut in functional genomics
}

\author{
Marzena Kurowska • Agata Daszkowska-Golec • \\ Damian Gruszka • Marek Marzec • Miriam Szurman • \\ Iwona Szarejko • Miroslaw Maluszynski
}

Received: 18 April 2011 /Revised: 16 August 2011 /Accepted: 17 August 2011 /Published online: 13 September 2011

(C) The Author(s) 2011. This article is published with open access at Springerlink.com

\begin{abstract}
Recent advances in large-scale genome sequencing projects have opened up new possibilities for the application of conventional mutation techniques in not only forward but also reverse genetics strategies. TILLING (Targeting Induced Local Lesions IN Genomes) was developed a decade ago as an alternative to insertional mutagenesis. It takes advantage of classical mutagenesis, sequence availability and highthroughput screening for nucleotide polymorphisms in a targeted sequence. The main advantage of TILLING as a reverse genetics strategy is that it can be applied to any species, regardless of its genome size and ploidy level. The TILLING protocol provides a high frequency of point mutations distributed randomly in the genome. The great mutagenic potential of chemical agents to generate a high rate of nucleotide substitutions has been proven by the high density of mutations reported for TILLING populations in various plant species. For most of them, the analysis of several genes revealed 1 mutation/200-500 kb screened and much higher densities were observed for polyploid species, such as wheat. High-throughput TILLING permits the rapid and lowcost discovery of new alleles that are induced in plants. Several research centres have established a TILLING public service for various plant species. The recent trends in TILLING procedures rely on the diversification of bioinformatic tools, new methods of mutation detection, including mismatch-specific and sensitive endonucleases, but also various alternatives for LI-COR screening and single nucleotide polymorphism (SNP) discovery using next-generation
\end{abstract}

M. Kurowska $\cdot$ A. Daszkowska-Golec $\cdot$ D. Gruszka $\cdot$ M. Marzec $\cdot$

M. Szurman · I. Szarejko • M. Maluszynski $(\bowtie)$

Department of Genetics, Faculty of Biology and Environmental

Protection, University of Silesia,

Jagiellonska 28,

40-032 Katowice, Poland

e-mail: miroslaw.maluszynski@us.edu.pl sequencing technologies. The TILLING strategy has found numerous applications in functional genomics. Additionally, wide applications of this throughput method in basic and applied research have already been implemented through modifications of the original TILLING strategy, such as Ecotilling or Deletion TILLING.

Keywords TILLING platform · Plant mutagenesis .

Bioinformatic tools $\cdot$ Reverse genetics $\cdot$ Next-generation sequencing technologies

\section{Introduction}

One of the most direct ways of establishing gene function is to identify a mutation in the specific gene and to link this mutation to the phenotypic change in the mutated organism. In the forward genetics approach ("from mutation through phenotype to the gene"), large mutated populations have been created and screened for alterations in the trait or biological process of interest. Over the decades, large mutant collections have been developed for many model organisms. These isolated mutants have then served for the identification of the genes underlying the change in phenotype. The sequence of the gene responsible for the altered phenotype can be isolated using the process of map-based cloning. Although this approach is both time-consuming and labour-intensive, it has been successfully applied for cloning several genes, even in species with large genomes, such as barley and wheat (Keller et al. 2005; Komatsuda et al. 2007; Krattinger et al. 2009; Zhang et al. 2009).

Recent advances in large-scale genome sequencing projects have opened up new possibilities for the application of mutation techniques in basic studies and in the improvement of crops. The reverse genetics strategy ("from 
gene sequence to phenotype") has widely replaced the forward approach in studies involved in detecting gene function. This strategy is based on the alteration of a gene structure or its activity, followed by an analysis of the associated change in plant phenotype. Several reverse genetics technologies, such as insertional mutagenesis with TDNA, transposon/retrotransposon tagging or gene silencing using RNA interference, have been proposed for plant functional genomics (for reviews, see: Alonso and Ecker 2006; Small 2007; Boutros and Ahringer 2008; Hirochika 2010; Bolle et al. 2011; Upadhyaya et al. 2011). However, the majority of these methods are fully applicable only for model plants with small genomes, such as Arabidopsis or rice, and even in these species, there are some drawbacks that limit their utilisation.

TILLING (Targeting Induced Local Lesions IN Genomes) was developed a decade ago as an alternative to insertional mutagenesis in Arabidopsis thaliana (McCallum et al. 2000). TILLING takes advantage of classical mutagenesis, sequence availability and high-throughput screening for nucleotide polymorphisms in a targeted sequence. It combines the high frequency of mutations induced by traditional mutagenesis with sensitive techniques for discovering single nucleotide mutations. The main advantage of TILLING as a reverse genetics strategy is that it can be applied to any plant species, regardless of its genome size, ploidy level or method of propagation. Chemical mutagens, which are usually used in TILLING protocols, provide a high frequency of point mutations distributed randomly in the genome. An analysis of mutations induced by ethyl methanesulphonate (EMS) in 192 Arabidopsis genes revealed about ten mutations per gene among the 3,000 $\mathrm{M}_{2}$ plants examined (Greene et al. 2003). It was estimated that each $\mathrm{M}_{2}$ plant carried, on average, 720 mutations (Till et al. 2003), while only 1.5 T-DNA insertions per mutant line were detected in the Arabidopsis insertion populations (Alonso et al. 2003). Thus, much smaller populations are required to reach saturation mutagenesis using TILLING-ca. 5,000 $\mathrm{M}_{1}$ plants in Arabidopsis (Østergaard and Yanofsky 2004) as compared to 360,000 lines in T-DNA mutagenesis (Alonso and Ecker 2006). The application of TILLING makes the functional analysis of large genomes as well as small genes, which are difficult targets for insertional mutagenesis, possible.

Another great advantage of TILLING technology relies on the ability of chemical mutagens to create a spectrum of mutations, including missense changes, truncation and mutations in splice junction sequences. In contrast to insertional mutagenesis that generates mostly gene knockouts, using TILLING, it is possible to induce a series of alleles in a targeted locus. In addition to loss-of-function alleles, chemical mutagens generate gain-of-function and hypomorphic alleles that can provide a range of phenotypes
(Alonso and Ecker 2006). The mutations are stable, which is not always the case for alternative methods of reverse genetics utilising RNAi silencing or transposon, e.g. Ac/Ds tagging. In addition, RNAi technology and insertional mutagenesis through T-DNA or transposon tagging relies on genetic transformation. TILLING does not require transformation and, thus, is the only reverse genetics strategy applicable for species that are not transformable or recalcitrant. It is recommended as non-GMO technology, so when using TILLING, GMO procedures and controversies are avoided. Moreover, TILLING is not technically demanding and can be performed at a relatively low cost.

The TILLING strategy was initially developed as a discovery platform for functional genomics, but it soon became a valuable tool in crop breeding as an alternative to the transgenic approach. The feasibility of TILLING has already been demonstrated for a large number of agronomically important crops, including rice, barley, wheat, maize, sorghum, soybean, rapeseed and tomato plants (Table 1). Large-scale TILLING services have also been created for model animal organisms such as Drosophila melanogaster, Caenorhabditis elegans, Danio rerio and Rattus norvegicus (Winkler et al. 2005; Gilchrist et al. 2006a; Wienholds et al. 2003; Smits et al. 2004, respectively).

The general protocol for the creation of a TILLING platform in plants includes the following steps (Fig.1):

1. Creation of mutated populations

- Chemical mutagenesis

- Development of $\mathrm{M}_{1}$ and $\mathrm{M}_{2}$ generations

- DNA extraction from individual $\mathrm{M}_{2}$ plants

- Creation of DNA pools of 5-8 $\mathrm{M}_{2}$ plants

- Setting up an $\mathrm{M}_{3}$ seed bank

2. Detection of mutations in a targeted sequence

- Polymerase chain reaction (PCR) amplification of the targeted DNA segment using pooled DNA as a template

- Detection of mutations using different procedures, e. g. cleavage by specific endonuclease, denaturing high-performance liquid chromatography (DHPLC) or high-throughput sequencing

- Identification of the individual $\mathrm{M}_{2}$ plant carrying the mutation

- Sequencing the target gene segment to confirm the mutation and to determine the type of nucleotide change

3. Analysis of the mutant phenotype

A mutated population becomes a TILLING platform when the DNA samples and seeds collected from a large $\mathrm{M}_{2}$ population are archived and put into databases. Usually, 


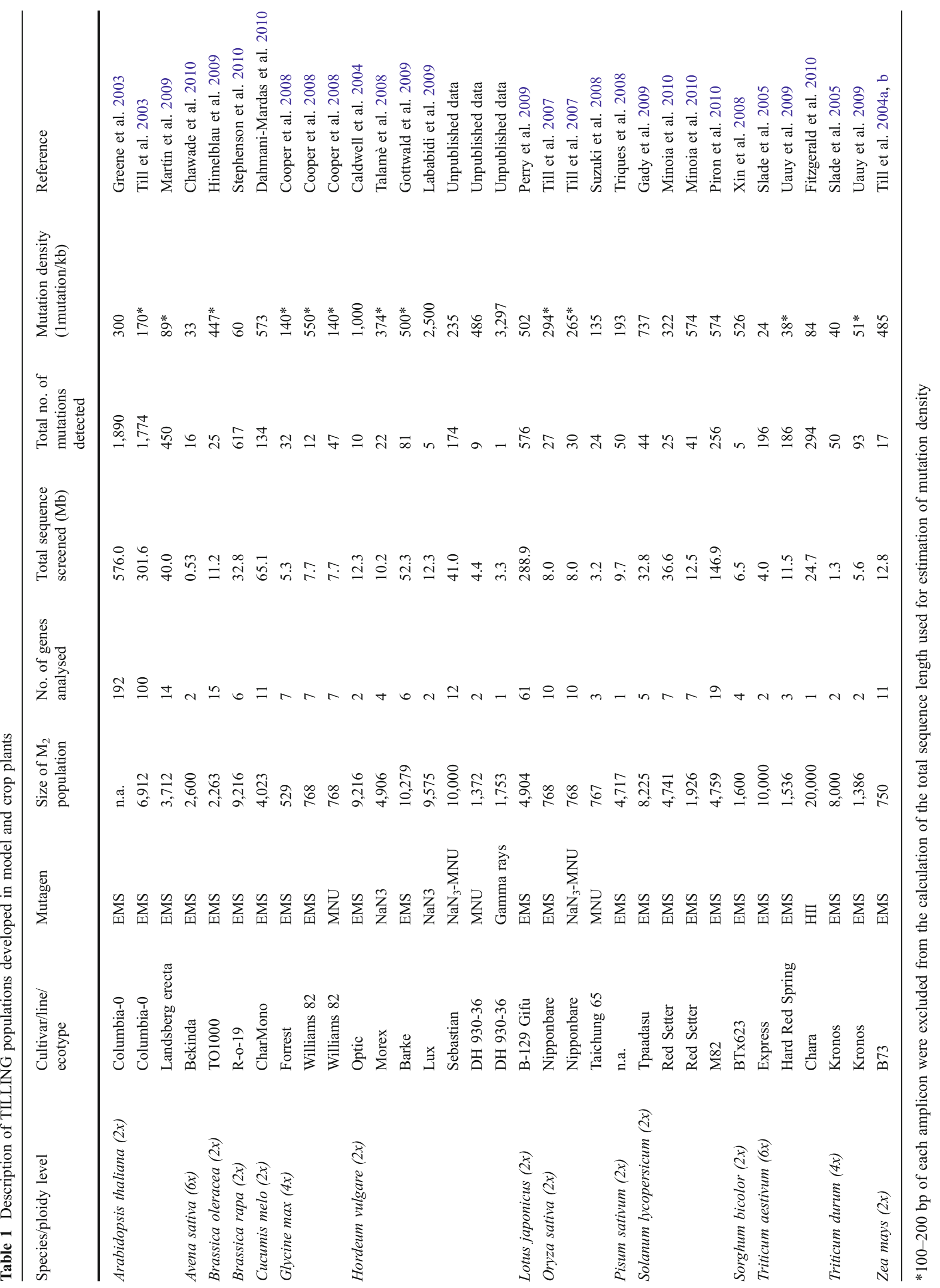




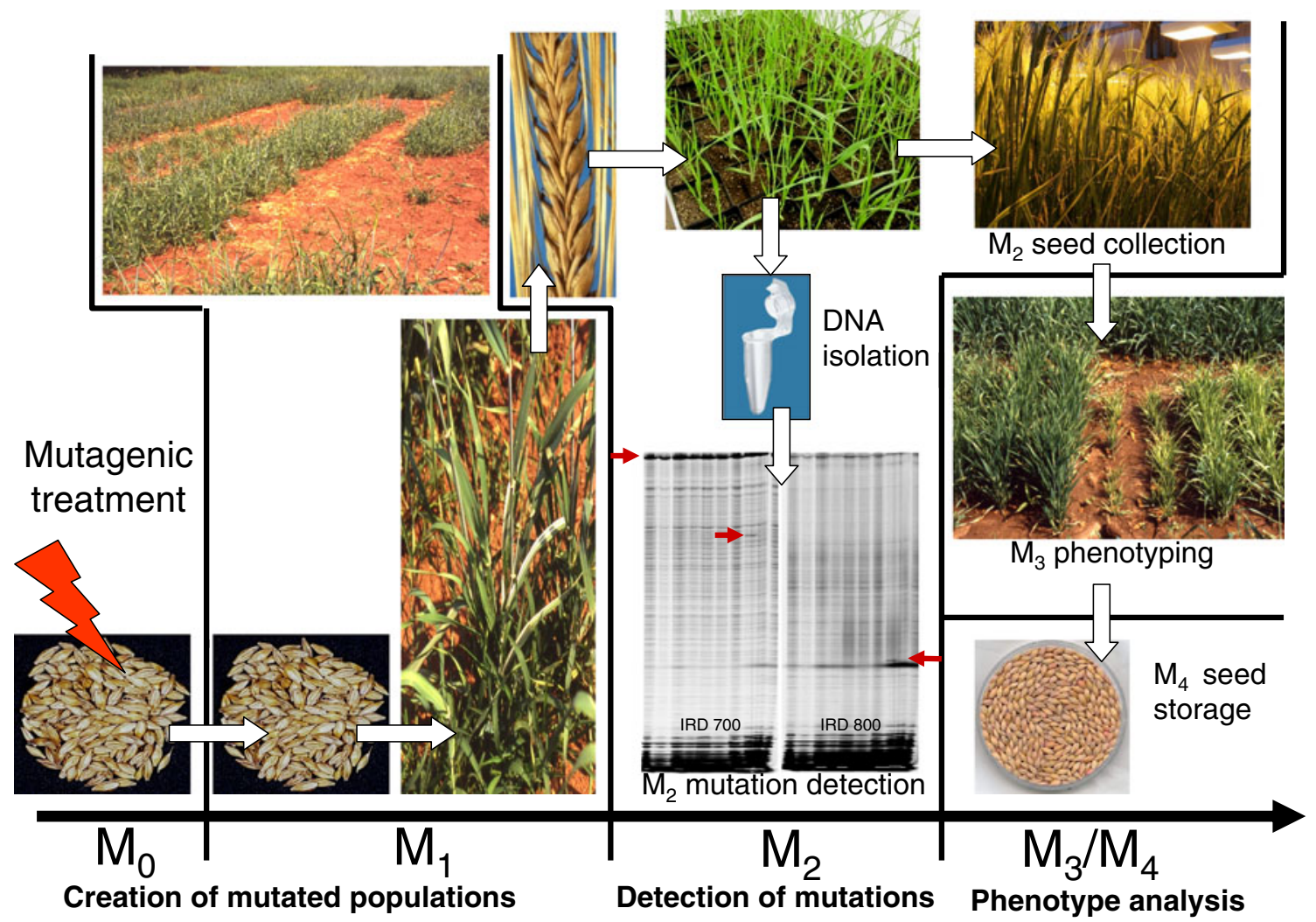

Fig. 1 Development of a TILLING platform in barley

platforms of 3,000-5,000 $\mathrm{M}_{2}$ individuals are created, although larger populations that include 10,000 plants have also been reported. Almost all TILLING populations were developed using chemical mutagens, among them, the alkylating agent (EMS) was most often applied. The great mutagenic potential of chemical agents has been proven by the high density of mutations reported for established TILLING populations (Tables 1 and 2).

Once established, the TILLING platform can serve as a permanent source of mutations for both forward and reverse genetics. In many cases, phenotypic observations of the $\mathrm{M}_{2}$ generation are performed and large $\mathrm{M}_{3}$ generations are generated for forward screening (Talamè et al. 2008; Wang et al. 2008a; Himelblau et al. 2009; Minoia et al. 2010). A detailed phenotypic evaluation of $\mathrm{M}_{2}$ and $\mathrm{M}_{3}$ progeny makes it possible to enrich the population that is screened for mutations in a specific gene, or for plants bearing a phenotypic change related to the studied metabolic or developmental process. Such an approach was successfully demonstrated by Perry et al. (2003) for the analysis of genes controlling the root symbiosis of Lotus japonicus using a TILLING population that was pre-selected for root nodulation mutants. Additionally, large $\mathrm{M}_{3}$ generations can provide a resource for the direct forward selection of mutants tolerant/hypersensitive to a range of abiotic and biotic stresses.
To facilitate the systematic gathering of information about the developed platform, including molecular and phenotypic data, TILLING databases are created and often made publicly available. Examples of such databases are presented in the further part of this paper, followed by a description of TILLING services, bioinformatic tools and methods of mutation detection, including the application of new generation technologies and modifications of the TILLING strategy. Presented below are also examples of the use of this technology in the creation of useful new alleles in many crop species, which are alternatives to the transgenic approach in plant breeding.

\section{TILLING platforms and services}

Creating a TILLING population requires that a lot of information to be collected in a relevant database. Most of the available databases contain data on 5,000 to 13,000 plants of the $\mathrm{M}_{2}$ population. It is necessary to keep a description of every plant phenotype, information on the availability of the DNA extracted from each plant and seeds in the seed bank in such a database and to systematically gather information about the molecular and genetic research that is being carried out. Furthermore, this data has to be saved properly, in order to allow the results to be searched 


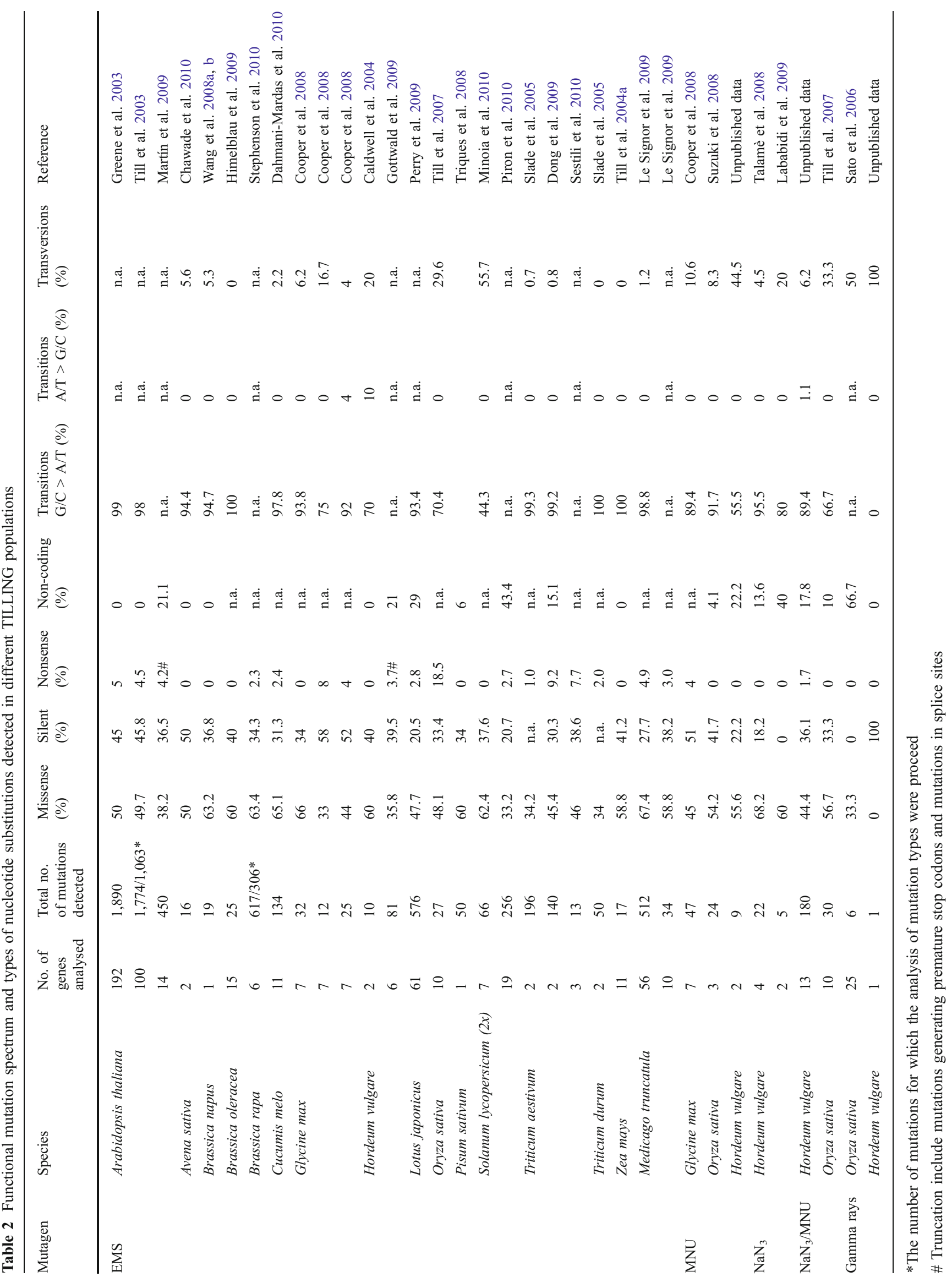


and sorted. That is why creating a database containing all of this information about the investigated plants is a very important part of every project involving the development of a TILLING platform. It is also desirable that such a database will be publicly available on the Internet. Most analyses of a phenotype apply to all stages of plant development and are divisible into very specific categories and subcategories. Typically, the main categories describe the attributes of the whole plant (e.g. time of flowering, size/height of plant, plant architecture) or individual plant organs (e.g. seeds, fruits, tillers, spikes), whereas subcategories apply to the phenotypes that have already been observed (e.g. leaf size, branching, abnormal spikes). The databases that are accessible on the Internet contain 48 to 107 subcategories grouped under various major categories. Additionally, descriptions of plants showing phenotypic changes have been supplied with photographic documentation. Some of the databases also contain information about genes that have already been analysed and any identified mutations in their sequences. In this case, the analysed sequence is entered into database with the identified mutations indicated and with information about its localisation in the exon or intron. Additionally, there is information about the nature of the mutation and its impact on the amino acid sequence and protein structure, if available.

Some publicly accessible databases may constitute independent websites, whose only purpose is to describe either the specific project (LycoTILL, http://www.agrobios. it/tilling) or several projects carried out by one team (UTILLdb, http://urgv.evry.inra.fr/UTILLdb). When creating meta-services involving a number of different databases that already exist on various aspects of studies on one organism, TILLING databases can also be included (MaizeGBD, http://www.maizegdb.org/). A common feature of all of the accessible TILLING databases is the information about the phenotype of the analysed plants. Teams that previously only shared information about identified mutations now update the databases with the results of phenotyping, including photos and a detailed description of any changes in the phenotype (e.g. the Maize TILLING Project). There are only a few databases related to TILLING projects that are accessible. These databases have been created at different times and by different teams; therefore. they differ greatly in their content and the available options for users (Table 3).

High-throughput TILLING permits the rapid and low-cost discovery of new induced alleles in plants. However, the creation of a large TILLING platform is a time-consuming, labour-intensive and expensive task. Several research centres from Europe and North America have established TILLING public services for various plant species: Medicago truncatula, L. japonicus and Brassica rapa at the John Innes Centre
(RevGenUK); Pisum sativum and Solanum lycopersicum at the French National Institute for Agriculture Research (INRA) (UTILLdb); Oryza sativa, S. lycopersicum and A. thaliana at the University of California; $A$. thaliana by the Seattle TILLING Project (STP); Zea mays at Purdue University; Glycine $\max$ at Southern Illinois University; Avena sativa at CropTailor AB; A. thaliana, B. oleracea and B. napus at the University of British Columbia (CAN-TILL); Hordeum vulgare at the Department of Agro-Environmental Sciences and Technology (DiSTA) of the University of Bologna (TILLMore: a TILLING resource in Barley Morex). Information about the assayed genes (TILLed genes) using the TILLING strategy is not always available on the websites because this information could be of commercial value. It is possible to order the TILLING analysis of any known gene that is involved in a process that is being investigated or a trait in particular species (Table 3). However, it is important to remember that knowing the genomic sequence of the chosen gene or genes is necessary and the user must decide whether the gene is a good candidate for TILLING. On the websites of the above-mentioned public services, the potential user can find all of the information which is necessary to start a project, e.g. how to find the best region of the gene to target and how design the proper primers using free web-based tools. Screening the selected region of the requested gene for mutations discovery is usually provided by the service. After analysis, the service provides the user with a list of mutations in the investigated sequence(s) and seeds of related mutants. In a short time, the scientists and plant breeders can take advantage of existing sources of the induced genetic diversity in those plant species for which commercial services are available. Several research centres have created TILLING populations for particular species and cultivars that are of interest. The results of these investigations can be found in related publications (Table 4).

\section{Mutagens}

Chemical mutagenesis causes both point mutations, which are irreversible and produced in relatively high densities, and also chromosome breaks that cause various chromosomal rearrangements, which can reduce fertility and affect lethality. Unlike insertional mutagenesis, the high density of chemically induced point mutations makes TILLING suitable for targeting small genes or single protein domains that are encoded by large genes (Till et al. 2003). In contrast to insertional mutagenesis, the TILLING strategy is general, because chemical mutagenesis has been successfully applied to most major taxa (Henikoff and Comai 2003). Alkylating agents are the most commonly applied chemicals in plant mutagenesis. They constitute a class of base-modifying compounds which directly alter the structure and properties of the bases. DNA 


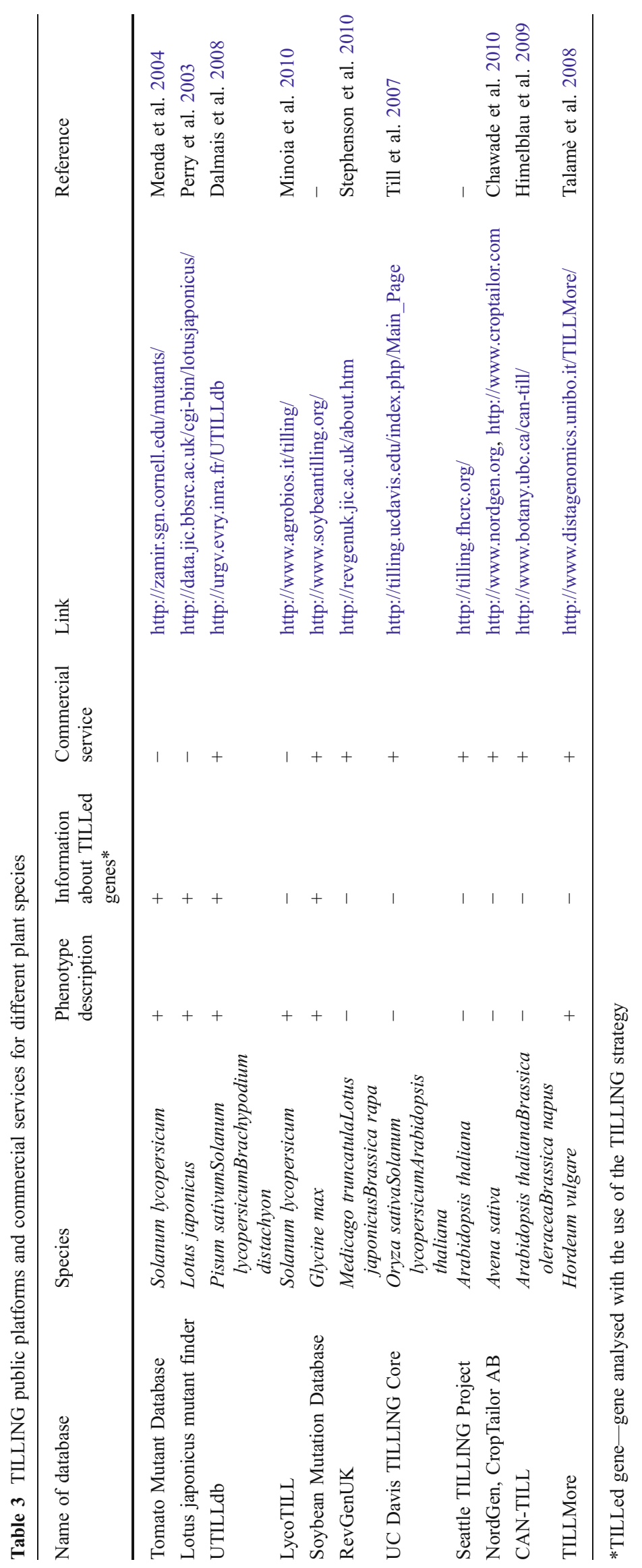


Table 4 TILLING populations of different plant species for which the databases and/or commercial services are not available on the Internet at present

\begin{tabular}{|c|c|c|c|}
\hline Species & Centre & Country & Reference \\
\hline \multirow[t]{4}{*}{ Arabidopsis thaliana } & Fred Hutchinson Cancer Research Center & USA & Greene et al. 2003 \\
\hline & Cereon Genomics & USA & Jander et al. 2003 \\
\hline & Fred Hutchinson Cancer Research Center & USA & Till et al. 2003 \\
\hline & $\begin{array}{l}\text { Departamento de Genética Molecular de Plantas, Centro Nacional } \\
\text { de Biotecnología (CNB) }\end{array}$ & Spain & Martín et al. 2009 \\
\hline Avena sativa & Department of Plant and Environmental Sciences, Goteborg University & Sweden & Chawade et al. 2010 \\
\hline Brassica oleracea & Department of Biology, California Polytechnic State University & USA & Himelblau et al. 2009 \\
\hline Brassica rapa & Department of Crop Genetics, John Innes Centre & UK & Stephenson et al. 2010 \\
\hline Cucumis melo & Unite de Recherche en Genomique Vegetale, INRA-UEVE-CNRS & France & Dahmani-Mardas et al. 2010 \\
\hline Glycine $\max$ & Fred Hutchinson Cancer Research Center & USA & Cooper et al. 2008 \\
\hline \multirow[t]{4}{*}{ Hordeum vulgare } & Scottish Crop Research Institute & UK & Caldwell et al. 2004 \\
\hline & $\begin{array}{l}\text { Department of Agroenvironmental Sciences and Technology, } \\
\text { University of Bologna }\end{array}$ & Italy & Talamè et al. 2008 \\
\hline & Leibniz Institute of Plant Genetics and Crop Plant Research (IPK) & Germany & Gottwald et al. 2009 \\
\hline & Department of Agriculture and Ecology, University of Copenhagen & Denmark & Lababidi et al. 2009 \\
\hline \multirow[t]{2}{*}{ Lotus japonicus } & The Sainsbury Laboratory & UK & Perry et al. 2009 \\
\hline & Metabolic Biology, John Innes Centre & UK & Vriet et al. 2010 \\
\hline Medicago truncatula & Department of Disease and Stress Biology, John Innes Centre & UK & Rogers et al. 2009 \\
\hline \multirow[t]{3}{*}{ Oryza sativa } & Graduate School of Agricultural Science, Tohoku University & Japan & Sato et al. 2006 \\
\hline & Fred Hutchinson Cancer Research Center & USA & Till et al. 2007 \\
\hline & Genetic Strains Research Center & Japan & Suzuki et al. 2008 \\
\hline \multirow[t]{3}{*}{ Solanum lycopersicum } & $\begin{array}{l}\text { Wageningen UR, Plant Breeding, Wageningen University and } \\
\text { Research Center }\end{array}$ & The Netherlands & Gady et al. 2009 \\
\hline & Metapontum Agrobios & Italy & Minoia et al. 2010 \\
\hline & Unité de Recherche en Génomique Végétale, UMR INRA-CNRS-Uni & France & Piron et al. 2010 \\
\hline Sorghum bicolor & Plant Stress and Germplasm Development Unit & USA & Xin et al. 2008 \\
\hline \multirow[t]{5}{*}{ Triticum aestivum } & Anawah Inc. & USA & Slade et al. 2005 \\
\hline & Plant Breeding Institute & Australia & Dong et al. 2009 \\
\hline & Department of Plant Sciences, University of California & USA & Uauy et al. 2009 \\
\hline & CSIRO Plant Industry & Australia & Fitzgerald et al. 2010 \\
\hline & Department of Agrobiology and Agrochemistry, University of Tuscia & Italy & Sestili et al. 2010 \\
\hline \multirow[t]{2}{*}{ Triticum turgidum } & Anawah Inc. & USA & Slade et al. 2005 \\
\hline & Department of Plant Sciences, University of California & USA & Uauy et al. 2009 \\
\hline Zea mays & Basic Sciences Division, Fred Hutchinson Cancer Research Center & USA & Till et al. $2004 \mathrm{a}$ \\
\hline
\end{tabular}

bases differ in their vulnerability to chemical modification by alkylating mutagens: ring nitrogens are more reactive than oxygens and the $\mathrm{N}^{7}$ position of the guanine and $\mathrm{N}^{3}$ position of the adenine are the most prone to modification. Alkylating agents cause every type of point mutation: transitions, transversions, deletions and frameshifts, as well as chromosome breakages (Maluszynski et al. 2003).

In the majority of TILLING experiments, especially those conducted on Arabidopsis, EMS has been applied as a mutagen. In addition to this species, EMS has been used as the mutagen in TILLING experiments performed on $B$. napus, B. oleracea, G. max, H. vulgare, L. japonicus, $M$. truncatula, O. sativa, Sorghum bicolor, Triticum aestivum, T. durum and Z. mays (Gilchrist and Haughn 2005; Martín et al. 2009). EMS-induced mutations are randomly distributed in the genome and a high degree of mutational saturation can be achieved without excessive DNA damage (Gilchrist and Haughn 2005). In Arabidopsis, 5\% of the mutations induced by this mutagen in coding regions result in the premature termination of the gene product (nonsense mutations) or mutations in splice sites, whereas ca. 50\% lead to missense mutations (Greene et al. 2003; Martín et al. 2009). EMS alkylates guanine bases and leads to mispairing: alkylated guanine pairs with thymine, which results mainly in $\mathrm{G} / \mathrm{C}$ to $\mathrm{A} / \mathrm{T}$ transitions (Henikoff and Comai 2003). This type of transition makes up more than 99\% of all EMS-induced mutations in Arabidopsis, maize and wheat. However, when the frequencies of various types 
of EMS-induced mutations were analysed in other species (tomato, rice and barley) $\mathrm{G} / \mathrm{C}$ to $\mathrm{A} / \mathrm{T}$ transitions constituted no more than $70 \%$ (Minoia et al. 2010). The discussed mutation percentages and frequencies are reported in Tables 1 and 2.

Another alkylating agent, $N$-methyl- $N$-nitrosourea (MNU, MNH), induced only $\mathrm{G} / \mathrm{C}$ to $\mathrm{A} / \mathrm{T}$ transitions in several TILLING experiments in G. $\max$ and $O$. sativa (Cooper et al. 2008 and Suzuki et al. 2008, respectively). The mutation frequency induced by this mutagen in G. $\max$ was comparable to the frequency induced in this species by EMS (1 mutation/140 kb) (Cooper et al. 2008). However, in rice, MNU-induced mutations had a frequency that was two times higher (1 mutation/135 kb) than EMS (1 mutation/ $300 \mathrm{~kb}$ ) (Till et al. 2007; Suzuki et al. 2008; Martín et al. 2009). However, it should be kept in mind that, in the case of the MNU treatment, the panicles were exposed to the mutagen, while in the EMS experiment, the seeds were treated with the mutagen. Another confirmation that the treatment procedure is crucial for the mutation frequency obtained is the comparison of mutation frequencies between two TILLING experiments in rice, both using MNU. In one of these experiments, rice panicles were treated with $1 \mathrm{mM}$ MNU (Suzuki et al. 2008), whereas in the second, the rice seeds were exposed to a combined treatment with $1 \mathrm{mM}$ of sodium azide and $15 \mathrm{mM}$ MNU (Till et al. 2007). The mutation frequency obtained after the treatment of the panicles was higher $(1$ mutation/135 kb) than the frequency which resulted from the combined treatment of the seeds (1 mutation/265 kb) (Suzuki et al. 2008 and Till et al. 2007, respectively).

Sodium azide, which has been used as the mutagen in several experiments, is a chemical compound that becomes mutagenic only in some organisms, e.g. Escherichia coli, Saccharomyces cerevisiae, $H$. vulgare, $O$. sativa and several other plant species, but does not increase mutation frequencies in A. thaliana and is only marginally mutagenic in humans and animals (Sadiq and Owais 2000). In barley, sodium azide is mutagenic in acidic $\mathrm{pH}(\mathrm{pH}=3)$ and it primarily induces $\mathrm{A} / \mathrm{T}$ to $\mathrm{G} / \mathrm{C}$ transitions. The frequency of chromosome breakage caused by sodium azide is relatively low (Maluszynski et al. 2003). Depending on the species, various concentrations of sodium azide and treatment times are used (for a review, see Gruszka et al. 2011). Apart from a combined treatment with MNU, sodium azide has also been applied in a TILLING experiment in barley, in which three different concentrations ( $1 \mathrm{mM}, 5 \mathrm{mM}$ and $10 \mathrm{mM})$ of sodium azide were used. Samples treated with these concentrations showed germination rates at similar levels of $85 \%, 82.5 \%$ and $81.3 \%$, respectively. Given the mutation density and acceptable lethal effect, a $10 \mathrm{mM}$ concentration of sodium azide was considered to be optimal (Talamè et al. 2008). The mutation frequency obtained in this experiment was 1 mutation/374 $\mathrm{kb}$ and was about three times higher than in the experiment in which EMS was applied as the mutagen ( 1 mutation/1 Mb) (Talamè et al. 2008 and Caldwell et al. 2004, respectively).

Physical mutagens, gamma-ray radiation and fast neutrons are also applied in functional genomics in plants. In order to create a TILLING population, seeds of japonica rice were irradiated with 500 Gy of gamma rays. The average size of the 25 rice genome regions tested in the experiment was $1.2 \mathrm{~kb}$. The mutation frequency was determined as 1 mutation/6.2 Mb. Four of the mutations identified were single nucleotide substitutions and two were 2-bp and 4-bp deletions. Among point mutations, transversions $(C / G$ to $A / T$ and $C / G$ to $G / C)$ are three times more abundant than transitions (mainly $\mathrm{C} / \mathrm{G}$ to $\mathrm{T} / \mathrm{A}$ ). Taking into account the results of various experiments using gamma radiation, half of the point mutations induced by this mutagen were deletions, which can cause a frameshift if located in exons. The detection rate of knockout mutations generated by this mutagen was much higher than in a TILLING experiment in which chemical mutagens were applied (Sato et al. 2006).

Deletion TILLING (De-TILLING; see below) utilises fast neutron bombardment to develop mutagenised populations (Li et al. 2001). Fast neutrons are a form of highenergy radiation which induces a broad range of deletions and other chromosomal mutations in plants. Several sources of fast neutrons are potentially available for mutagenesis, including particle accelerators and nuclear research reactors. Fast neutrons produced by nuclear fission are accompanied by gamma radiation; however, its contribution is adjustable. To generate short-range secondary particles within the cell nucleus which mediate DNA strand breakage, the neutron energy should be in the range of $500 \mathrm{keV}$ to $5 \mathrm{MeV}$. De-TILLING mutants offer advantages for crop improvement, as they possess relatively fewer background mutations (Rogers et al. 2009). Deletional mutagenesis may be the best way to knock out tandemly repeated genes, which are common in plant genomes (Achaz et al. 2001; Li et al. 2001).

The two chemical mutagens that are the most widely used in TILLING experiments in animals are $N$-ethyl- $N$ nitrosourea (ENU) and EMS. The former induces both transitions and transversions $(\mathrm{G} / \mathrm{C}$ to $\mathrm{C} / \mathrm{G}$ and $\mathrm{A} / \mathrm{T}$ to $\mathrm{C} / \mathrm{G})$; however, $\mathrm{G} / \mathrm{C}$ to $\mathrm{A} / \mathrm{T}$ transitions are in the majority (Maluszynski et al. 2003). ENU induces high frequencies of point mutations and is a more potent mutagen than EMS. ENU, which is an alkylating agent, leads to mispairing and, ultimately, results in base pair substitutions and, sometimes, base pair losses (Guénet 2004). In the cases of rats ( $R$. norvegicus) and mice (Mus musculus), ENU is supplied at the dose of $50-100 \mathrm{mg} / \mathrm{kg}$ (Smits et al. 2004 and Nolan et al. 2000, respectively), whereas in a zebrafish (D. rerio) 
TILLING experiment, the mutagen was applied at a concentration of $3 \mathrm{mM}$ (Wienholds et al. 2003). In rodents, the average density of ENU-induced mutations was 1 mutation/2.3 $\mathrm{Mb}$ (in rats) and 1 mutation/ $1 \mathrm{Mb}$ in mice (Smits et al. 2004 and Nolan et al. 2000, respectively). The density of ENU-induced mutations in the zebrafish genome was significantly higher and was determined as 1 mutation/ $235 \mathrm{~kb}$ (Wienholds et al. 2003).

The second alkylating agent used in TILLING experiments in animals is EMS. However, this mutagen is predominantly used in D. melanogaster and C. elegans. During the mutagenesis procedure in TILLING experiments in $D$. melanogaster, the mutagen was used at a concentration of $50 \mathrm{mM}$, whereas in $C$. elegans, the mutagen concentration was $25 \mathrm{mM}$. As far as mutation densities are concerned, it was determined as 1 mutation/150 kb in D. melanogaster (Winkler et al. 2005), whereas the mutation frequency in $C$. elegans was 1 mutation/293 kb (Gilchrist et al. 2006a).

\section{Bioinformatic tools in the TILLING strategy}

The bioinformatic tools are used in the TILLING strategy from the beginning, when the candidate gene is the newly identified homologue and the amplicon is determined, till the end, when the analysis of obtained alleles are performed in terms of their impact on protein function. It is important to state that there is no need to know the full genome of the studied species in order to analyse it with the TILLING strategy. The sequence of the gene of interest can be retrieved for many species from databases, such as GenBank (http://www.ncbi.nlm.nih.gov/genbank/) and then a proper homologue can be identified. In the case of barley, whose genome is not fully sequenced, cloning homologues enables their functional analysis. Candidate genes for analysis, when not available for particular species, as e.g. in barley, can be retrieved from GenBank database of Arabidopsis or rice. Afterwards, in the case of Arabidopsis genes, a BLAST search is performed against the rice genome to identify the rice homologue. In order to amplify the coding sequence of a proper homologue, it is necessary to use mRNA and amino acid sequences as a queries in the barley EST databases. The most popular EST databases are TIGR Plant Transcript Assemblies (http://plantta.jcvi.org/), with 456,410 barley EST records (latest update July, 2007), and Computational Biology and Functional Genomics Laboratory (http://compbio.dfci.harvard.edu), with 502,606 barley EST records (latest update March, 2011). EST sequences with the highest similarity are chosen as a template to design primers in order to amplify them. Assembling of the amplified sequences into a barley coding sequence is achieved by using several tools, e.g. CodonCode Aligner (http://www. codoncode.com/aligner), which is able to align and put together contigs into one consensus sequence. The obtained full barley coding sequence is then aligned with the rice genomic sequence in order to establish putative borders between exons and introns. It can be performed using the BLASTN algorithm or software such as Splign (http://www. ncbi.nlm.nih.gov/sutils/splign/splign.cgi). The latter additionally makes a graphic model of the gene (Kapustin et al. 2008). It enables the designing of primers in order to confirm experimentally intron presence or absence. Again, the assembling of contigs into a full genomic sequence can be performed with the use of CodonCode Aligner. For the purpose of obtaining the barley gene model, coding and genomic sequences are aligned with the use of BLASTN or Splign software. Based on the coding sequence, the amino acid sequence is determined via in silico translation. The last step is the confirmation of the orthology character of a cloned homologue using GreenPhyl (http://greenphyl.cirad. $\mathrm{fr} /$ ). GreenPhyl contains gene sequences automatically clustered from 12 complete plants' genomes.

The determination of an amplicon is a crucial step for TILLING analysis. The selection of a suitable amplicon provides a higher probability to identify changes in the DNA sequence with an impact on the protein function during TILLING screenings. It is worthwhile to choose a fragment as much as possible within the coding region. The second condition is to identify the region with the most potential to generate deleterious changes. This can be achieved with software such as CODDLE (Codons Optimized to Discover Deleterious LEsions; http://www.proweb.org/coddle/coddle help.html). CODDLE performs BLAST alignment in order to identify a conserved region, uses SIFT (Sort Intolerant From Tolerant) and PSSM (Position-Specific Scoring Matrix). In addition to CODDLE analysis, the alignment of genomic and amino acid sequences from closely related species with the use of BLASTN and ClustalW2 (http://www.ebi.ac.uk/Tools/ msa/clustalw2/), respectively, can be performed.

Each of the identified alleles is then analysed in terms of influence protein. A bioinformatic tool designed for displaying and analysing nucleotide polymorphisms is PARSESNP (Project Aligned Related Sequences and Evaluate SNPs; http://www.proweb.org/parsesnp/parsesnp_help.html; Taylor and Greene 2003). PARSESNP determines the effect of single nucleotide polymorphisms (SNPs) on protein, based on the alignment of related proteins with the use of PSSM and SIFT. Sequence alignments are converted to the Blocks format and then to PSSM. PSSM is aligned to the gene with the use of the Multiple Alignment Search Tool (MAST). It determines mapping of PSSM onto a sequence. Large positive PSSM $(>10)$ means that missense change in the analysed sequence of the DNA can be dramatic for protein function. SIFT allows to predict the severity of change; a SIFT score lower than 0.05 could have the same effect as a PSSM higher than 10. Another feature of PARSESNP is 
the ability to predict changes in the restriction enzyme recognition sites.

Before starting to phenotype plants carrying mutations identified during the TILLING screenings, it is possible to predict the putative effect of mutation on the secondary structure of proteins. There are several bioinformatic tools used for this purpose. Commonly used are SAS (Sequence Annotated by Structure; http://www.ebi.ac.uk/thornton-srv/ databases/sas/; Milburn et al. 1998) and SOPMA (SelfOPtimized Method for secondary structure prediction with Alignment) http://npsa-pbil.ibcp.fr/cgi-bin/npsa_automat.pl? page=npsa_sopma.html; Geourjon and Deléage 1995). Both SAS and SOPMA are based on protein alignment algorithms. For proteins containing transmembrane domains, it is worth analysing whether gene products encoded by identified alleles still have these domains. For hydropathy plotting, there are plenty of different software programs available online, e.g. Kyte Doolittle (http://gcat.davidson.edu/rakarnik/ kyte-doolittle; Kyte and Doolittle 1982). Kyte Doolittle calculates the hydropathy plot on the basis of the average hydrophobicity of all amino acids of the studied protein (Fig. 2).

Analysis in silico is also performed for these mutations that were identified in the non-coding region in terms of putative alternative splicing events. One of the available tools is ASD (Alternative Splicing Database, http://www. ebi.ac.uk/asd/; Thanaraj et al. 2004; Stamm et al. 2006), which analyses introns with SNPs in order to find an impact on the donor/acceptor site, polypyrimidine tract or branch point. It needs to be underlined that all in silico data performed with the use of bioinformatic tools has to be verified experimentally by phenotyping each mutant.

\section{TILLING protocol-cheaper over time}

Mismatch-specific and sensitive endonucleases

The first strategy that was described for the TILLING procedure (McCallum et al. 2000) included the EMS treatment of Arabidopsis seeds, DNA isolation and pooling, PCR reaction of the fragment of interest, heteroduplex formation and the identification of heteroduplexes using DHPLC. Since then, TILLING has been used with many different organisms and many modifications to the procedure have been introduced that help to automate the screening of mutations and reduce its cost. Over time, the DHPLC method for detecting mutations in the TILLING approach was, in most cases, replaced by the digestion of heteroduplexes using specific endonucleases followed by polyacrylamide electrophoresis and visualisation in the very sensitive LI-COR gel analyser system (LI-COR Biosciences), which is less expensive and faster than DHPLC (Colbert et al. 2001; Till et al. 2006a). Single-stranded specific endonuclease has been used to cleave heteroduplex DNA at the mismatch site in the TILLING procedure. The most popular mutation detection method for TILLING is a mismatch cleavage assay using the endonuclease CEL I from celery in plants (Gottwald et al. 2009), animals (Wienholds et al. 2003) and humans (Till et al. 2006b). CEL I-like nucleases are also found in other plant species: alfalfa, asparagus and tomato. There is one report of using CEL I extracted from the petioles of B. rapa (Sato et al. 2006). There are other single-stranded-specific nucleases, such as: S1 from Aspergillus oryzae, P1 form Penicillium citrinum and mung bean nuclease from the sprouts of Vigna radiata, but they are
Fig. 2 Example output of analysis using the $\mathrm{KD}$ software. A value higher than 1.7 for the window size of 19 indicates the transmembrane domain

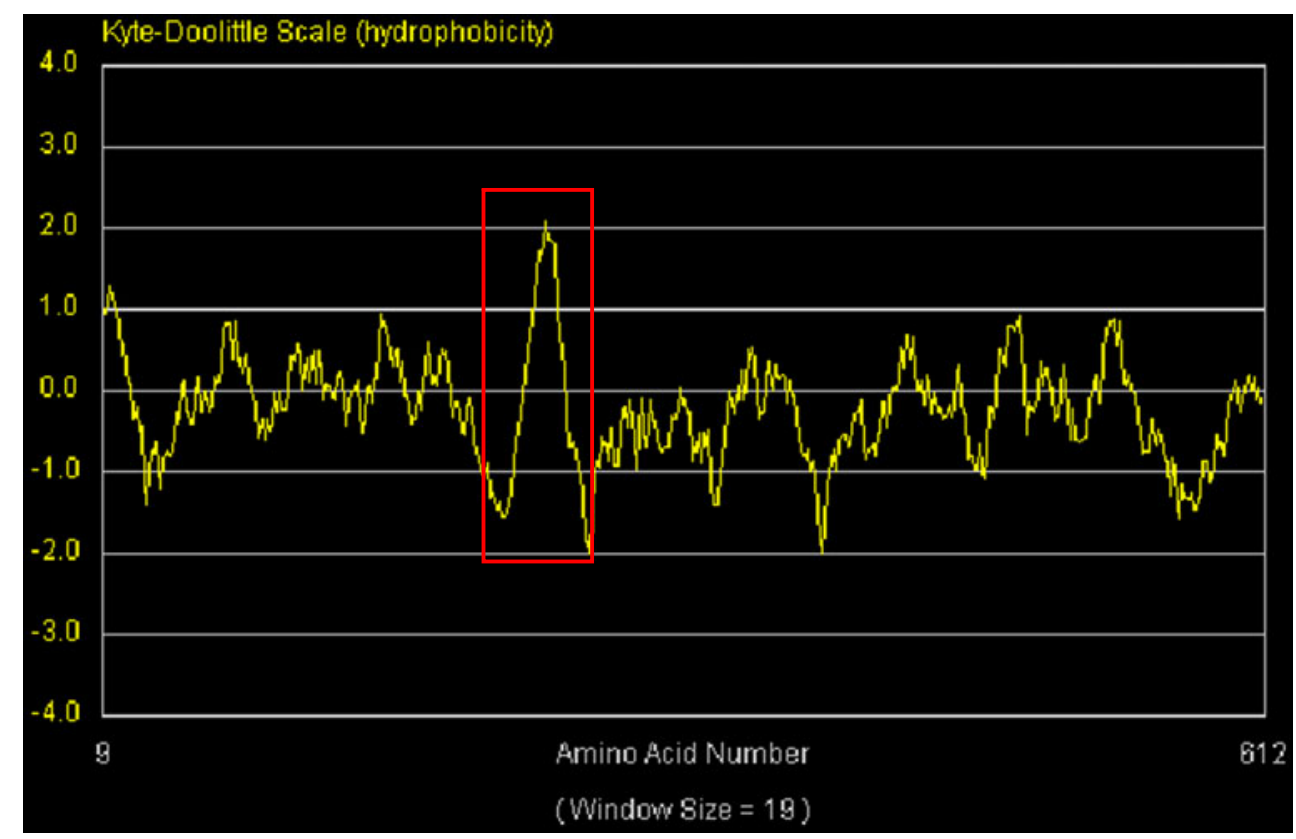


mainly active near $\mathrm{pH}$ 5.0. The neutral $\mathrm{pH}$ optimum incision, which occurred primarily at the phosphodiester bond immediately on the $3^{\prime}$ side of the mismatch and stimulation of activity by a DNA polymerase, are properties that distinguish CEL I from the above-mentioned nucleases (Oleykowski et al. 1998). The successful use of purified nucleases derived from mung bean sprouts (Till et al. 2004b; Kadaru et al. 2006) and Aspergillus (S1) (Till et al. 2004b) has also been reported in TILLING. ENDO I from $A$. thaliana is another mismatch-specific endonuclease that belongs to the S1 type. The application of ENDO I has been reported in mutation diagnostics in humans, the fingerprinting of complex populations of viruses, TILLING in P. sativum (Triques et al. 2007, 2008) and S. lycopersicum (Minoia et al. 2010) and Ecotilling (see below) in A. thaliana (Triques et al. 2008).

At the beginning, the most time-consuming step of this method was the cleavage of heteroduplex using a purified enzyme which was, and still is, an expensive reagent. A few years later, it was discovered that crude celery juice extract could also be used for mismatch cleavage and that its endonuclease activity is the same or even higher than in the case of the purified enzyme. The process of preparing it from celery is simple and very cheap, and takes less than two days. The protocol for crude celery juice extract isolation is based on a series of dialyses of the extract directly after juicing the celery. Once isolated, celery juice extract can be used for up to a few years when stored at $-80^{\circ} \mathrm{C}$ (Till et al. 2004b). However, it should be remembered that techniques employing mismatch-specific cleavage enzymes are often limited, as some enzymes do not recognise all mismatch types, have a low sensitivity in detecting one allele in a pool of DNA or lead to a high gel background caused by nonspecific cleavage (Triques et al. 2007). To perform TILLING in a cost-effective manner, the purification procedure can also be improved. Sephadex plates can be used as a most effective tool for the purification of PCR products after digestion, but there are also some different methods, e.g. ethanol, which is much cheaper and the efficiency of its action is approximately the same.

\section{Alternatives for LI-COR screening}

An alternative method of analysing mutations without using LI-COR screening for which labelled, and, therefore, expensive, primers are required can be the use of nondenaturing polyacrylamide gels with ethidium bromide staining, which was found to have an almost similar sensitivity as traditional LI-COR analysers. This modified TILLING approach was performed in wheat (Uauy et al. 2009). A modified TILLING system using non-labelled primers and fast capillary gel electrophoresis was applied in O. sativa (Suzuki et al. 2008). This system has several advantages compared to electrophoresis on a flat glass plate gel: a rapid separation and easier detection of digested fragments on chromatographic images, but a lower sensitivity of detection based on an emission signal from the ethidium bromide intercalation. Also, a mutation scanning method that does not rely on fluorescent primers was implemented by Caldwell et al. (2004). This is based on the double-stranded cleavage of heteroduplex molecules with CEL I nuclease with subsequent fragment detection using a Transgenomic WAVE High Sensitivity denaturing High Performance Liquid Chromatography (WAVEHS dHPLC) system. Another example is the high-throughput capillary electrophoresis system (AdvanceCE ${ }^{\mathrm{TM}}$ FS96, Advanced Analytical), which appears to be an investment that can reduce the costs and, most importantly, the time needed to detect mutations. Using this system, the purification step does not have to be performed, which decreases the time needed and the electrophoresis takes about a fifth of the time compared to using LI-COR scanners. Moreover, the PCR reaction is cheaper because the primers used are not labelled, the endonuclease is provided in the reagent kit and the process of loading samples for electrophoresis is automated (C. Weil, personal communication).

Other possible inexpensive alternatives are agarosebased detection systems containing SYBR Green I dye, which was used in O. sativa (Sato et al. 2006) or thin agarose gels $(<4 \mathrm{~mm})$ with ethidium bromide in $T$. aestivum (Dong et al. 2009). This system may have a lower sensitivity for the detection of mutations in comparison to a system using the LI-COR gel analyser. DEco-TILLING (double stranded Eco-TILLING) is an inexpensive method that involves complete digests of both strands at all mispaired sites in a DNA heteroduplex and was applied to SNP discovery in chum salmon (Oncorhynchus keta) using agarose gel electrophoresis with ethidium bromide (Garvin and Gharrett 2007). An alternative approach to mismatch detection was introduced by Cross et al. (2008) for O. sativa, EMAIL (Endonucleolytic Mutation Analysis by Internal Labelling), in which amplicon labelling is achieved via the incorporation of fluorescently labelled deoxynucleotides.

Although CEL I-based TILLING is very efficient for detecting mutations, alternative screening platforms have been established, like High Resolution DNA Melting Analysis (HRM) and Conformation Sensitive Capillary Electrophoresis (CSCE). While classical TILLING involves critical and time-consuming steps such as endonuclease digestion reactions and gel electrophoresis runs, when using CSCE or HRM, the only step required is a simple PCR before either capillary electrophoresis or DNA melting curve analysis. HRM depends on the loss of fluorescence from intercalating dyes (LCgreen Plus ${ }^{+\mathrm{TM}}$ molecules) bound to double-stranded DNA during thermal denaturation. The release of the dye results in decreased fluores- 
cence that is recorded as a melting curve by the LightScanner ${ }^{\circledR}$. Pools containing mutations form heteroduplexes in the post-PCR fragments mix. These are identified as differential melting temperature curves in comparison to homoduplexes. CSCE depends on the different speeds of the migration of heteroduplexes as compared to homoduplexes. The electrophoresis is performed in ABI $3130 \times \mathrm{L}$ capillaries filled with a semi-denaturating polymer, thus, allowing the identification of the pools containing a mutation within the targeted fragment. The disadvantage of the CSCE method is the short lengths of the target fragments, between 200 to $500 \mathrm{bp}$, compared to CEL I LI-COR platforms, where it is possible to screen for fragments up to $1.5 \mathrm{~kb}$ in one run. The CSCE and HRM methods were used for mutation screening in tomato plants (Gady et al. 2009). Combining HRM scanning with sequence analysis using Mutation Surveyor was applied in wheat (Dong et al. 2009). Mutation Surveyor is commercially available software for DNA variation analysis that allows automatic mutation detection in sequence traces. HRM analysis was also employed for the detection of mutations in the medaka (Oryzias latipes, Japanese killifish) TILLING library (Ishikawa et al. 2010). The same technique (HRM) was used in iTILLING (see below) (Bush and Krysan 2010).

\section{iTILLING}

A new approach to the TILLING method that reduces costs and the time necessary to carry out mutation screening was developed for Arabidopsis and it is called iTILLING, individualized TILLING (Bush and Krysan 2010). In the traditional method, the $\mathrm{M}_{2}$ plants are grown in soil and DNA is isolated from them individually and then pooled in order to perform PCR-based mutation detection (McCallum et al. 2000). With the iTILLING strategy, seeds from $\mathrm{M}_{1}$ are collected in bulk and cataloguing of the plants is not necessary. The $\mathrm{M}_{2}$ plants are grown one or two per well on 96-well spin plates on agar plugs and the tissue for DNA isolation is harvested directly from the plates using the IceCap method (Krysan 2004; Clark and Krysan 2007). The name Ice-Cap indicates that ice is used to capture the tissue samples. The roots of seedlings grow through the agar towards a second 96-well plate that is filled with water and, after approximately 3 weeks, reach the bottom of the second plate. The lower plate with the root fragments inside is then frozen and separated from seedlings. This plate serves as a platform for DNA isolation from the root tissue. The seedlings of plants remain intact. Isolated DNA is directly used as a template for PCR reactions and the mutation screening procedure can be performed. In the case of iTILLING, a high-resolution melt curve analysis of amplified fragments is performed in order to reveal mutations without using enzymatic cleavage and gel electrophoresis. Since there are two plants grown in each well, the isolated DNA is already pooled 2-fold; therefore, the identification of mutations in both heterozygous and homozygous states is possible. When seeds are sown one per well, only heterozygous mutations can be detected. After the mutation is discovered, the corresponding seedling(s) is transferred from the 96-well plate to the soil and grown in order to characterise its phenotype and to produce further generations (Bush and Krysan 2010). The same strategy of pooling tissue samples instead of nucleic acid from individual plants in the 96-well plate followed by DNA isolation from the arrayed samples was recently reported in tomato plants as NEATTILL, a simplified procedure for nucleic acid extraction from arrayed tissue for TILLING (Sreelakshmi et al. 2010). The iTILLING strategy is supplemental to the traditional TILLING approach. Although it reduces the investment required, it can only be performed for a small number of genes because the screening population used is of a short-lived nature and only plants with mutations that can be identified in a relatively short time can be grown to reach maturity and yield seeds for storage. The iTILLING strategy has already been successfully applied to many different species in a number of laboratories. Because the cost of this method has been reduced over time, iTILLING could well become the most common strategy of reverse genetics.

\section{Variant discovery in plants using next-generation sequencing technologies}

The advances in DNA sequencing technologies have been used in two ways in the TILLING strategy. Firstly, the growing number of whole-genome sequencing projects (for a review, see Mochida and Shinozaki 2010) in plants for both crop and model species has led to an increase in the possible choices of target genes in TILLING. Secondly, new strategies for sequencing, so called next-generation sequencing methods (NGS), which has been applied to a limited number of sequenced individuals using Sanger's method, can be used for direct mutation determination without any pre-screening. The advent of NGS platforms has dramatically increased the speed at which a DNA sequence can be acquired and has also reduced the cost of sequencing by more than two orders of magnitude (Deschamps and Campbell 2010). The NGS platforms, which are available today, include the 454 Genome Sequencer FLX and its smaller version, the GS Junior System, both of which are pyrosequencing-based instruments (Roche Applied Science; http://454.com/products/ index.asp), the Solexa 1 G Genome Analyzer (Illumina; http://www.illumina.com), the SOLiD instrument (Applied Biosystems; https://products.appliedbiosystems.com) and 
the HeliScope Single Molecule Sequencer (Helicos; http:// www.helicosbio.com).

\section{Application of NGS in TILLING}

Although there are not many examples of using NGS in the TILLING strategy for mutation detection to date, the situation may be much different in the future because the potential of those methods is great. The cost of the required equipment and reagents are still the drawbacks that limit their application. The number of nucleotides which can be sequenced in one run is large, but the number of identification tags ("sample bar coding") is limited. The technical requirements are also quite high. The analysis of the results of sequencing using NGS methods is also not very simple because it is necessary to distinguish between the false-positive and real SNPs. Rigola et al. (2009) used the 454 Roche technology for mutation detection in a tomato population obtained after EMS treatment and identified two mutations in the eIF4E gene based on the screening of more than $3,000 \mathrm{M}_{2}$ families in a single GS FLX sequencing run. There is also information on the website on the TILLING service, UC Davis TILLING Core. They have converted from LI-COR-CELI assays for the detection of mismatches to the NGS of pooled genes using the Illumina GAII platform (http://tilling.ucdavis.edu/ index.php/How_to_Get_TILLING). The same platform was used by the teams of L. Comai (University of California, Davis); J. Dubcovsky (University of California at Davis); S. Henikoff (Fred Hutchinson Cancer Research Center, Seattle); R. Tran and D. Lin (University of California, Davis), working under the project DBI-0822383 "Efficient identification of induced mutations in crop species by ultrahigh-throughput DNA sequencing" of the National Science Foundation, USA, which has led to the application of this technology in TILLING as well.

\section{Modifications of the TILLING strategy}

\section{Ecotilling - discovery of SNPs in natural populations}

One of the first modifications of the TILLING strategy, called Ecotilling, was proposed by Comai et al. (2004). In this modification, mutation detection technology was used to discover polymorphisms in a natural population of $A$. thaliana. Instead of using pools of DNA from mutagenised plants as templates, the DNA of $A$. thaliana ecotypes, each mixed with a reference Columbia ecotype DNA, was used. The authors discovered 55 haplotypes in five genes in more than 150 individuals, ranging from sequences differing by a SNP to those representing complex haplotypes. Ecotilling enables the rapid detection of variations in many individ- uals and is cost-effective because only one individual for each haplotype needs to be sequenced. The technology is applicable to any organism, including those that are heterozygous or polyploid. The next reports for a cultivated species appeared a short time later, and it was found out that this method could have practical applications in plant breeding, e.g. in the searching for resistance to new viruses or to create genetic diversity, which is important from an agronomic point of view. The wild relatives of cultivars, which have limited genetic diversity, could also be explored using this method and natural alleles could be detected. In the future, the genetic resources discovered by Ecotilling can be exploited in new cultivars. To date, many important EcoTILLed genes have been screened in natural populations of different species: FAE1 (fatty acid elongase 1), which is involved in the control of erucic acid synthesis in Brassica species (Wang et al. 2010); Alk, which encodes soluble starch synthase IIa in O. sativa (Kadaru et al. 2006); Ara d 2.01 (conglutin gene), the orthologue of Ara h 2.01, which codes the seed storage protein in Arachis duranensis, which is a very potent allergen for humans (Ramos et al. 2009); and Pina-D1 (puroindoline a) and Pinb-D1 (puroindoline b), which mainly condition kernel hardness through allelic variations in these genes in T. aestivum (Wang et al. 2008b). Another important target for agriculture could be a resistance to herbicides. Several classes of herbicides are known to inhibit the ALS (acetolactate synthase) gene. These highly selective $A L S$-inhibiting herbicides are very valuable for the weed management for a wide range of crops worldwide. Ecotilling was used for the detection of single nucleotide mutations in the $A L S$ genes of sulfonylurea (SU)resistant (R) Monochoria vaginalis (Pontederiaceae), a paddy weed in Japan. Genomic DNA of an SU-R plant (target DNA) was mixed with the DNA of an SU-susceptible (S) plant (reference DNA). Ecotilling detected two nucleotide mutations in the $A L S$ gene of SU-R M. vaginalis; this type of mutation has been reported to result in insensitivity to SUs in many weed biotypes (Wang et al. 2007).

Another valuable application of Ecotilling is searching for new virus-resistant alleles because natural populations are rich genetic resources and could be used to reach this goal. Translation initiation factors of the $4 \mathrm{E}$ and $4 \mathrm{G}$ protein families mediate resistance to several RNA plant viruses in natural crop diversity (Nieto et al. 2007). Nucleotide changes in the genes eIF4E and eIF(iso) $4 E$ of translation initiation factors have been detected in Capsicum annuum (Ibiza et al. 2010). Moreover, the utility of these new allelic variants have been demonstrated by testing them for PVY (Potato virus Y) resistance. Five new resistance alleles of the $I F 4 E$ gene have been detected. The same gene eIF4E, which controls resistance to MNSV (Melon necrotic spot virus), was screened in Cucumis species (Nieto et al. 2007). One new allele from Cucumis zeyheri, a wild relative of 
melons, has been characterised and it may be responsive for resistance to MNSV. Ecotilling was also used to identify allelic variation within the powdery mildew resistance genes mlo and Mla in H. vulgare (Mejlhede et al. 2006). This method not only confirmed the appearance of different alleles, but it also found that these differences can be used as a powerful genetic marker. Ecotilling offers the possibility of combining different $m l o$ alleles with different Mla alleles in order to obtain cultivars with a more durable resistance. Ecotilling has also been used in Solanum tuberosum (Elias et al. 2009) and Musa species diploid and polyploid accessions (Till et al. 2010).

Ecotilling could also be used in animal species as well as in plant species. Rare human nucleotide polymorphisms were discovered using this method (Till et al. 2006b). An ongoing problem in the application of Ecotilling for large mutation screening projects in humans is the lack of bioinformatics support for a quick and comprehensive evaluation of each newly found SNP. Coassin et al. (2008) proposed a solution to deal with the results and interpreting the possible functions of new variants by applying freely available software tools.

Ibiza et al. (2010) reported a modification of Ecotilling in which cDNA instead of genomic DNA was used. This approach avoids intron sequences and reduces the difficulty of amplifying target genes from different species. However, non-coding regions provide more variation and may, therefore, be more useful for mapping and genotyping (Gilchrist et al. 2006b).

\section{Ecotilling in ecology}

The ecotilling strategy could be used in ecology for studying population structures and evolutionary relationships. Wang et al. (2010) collected 116 accessions of modern cultivars of $B$. napus, $B$. rapa and B. oleracea. Variations in two paralogues, B. napus FAE1 (fatty acid elongase 1), among these cultivars were detected using Ecotilling. A phylogenetic tree of FAE1s indicated that the divergence between the $\mathrm{A}$ and $\mathrm{C}$ genome occurred later than the one between Arabidopsis and Brassica species; 18 SNPs were found in the coding region of FAE1 and may be used as genome-specific markers to distinguish the $\mathrm{A}$ and $\mathrm{C}$ genomes. Ecotilling was also used as a tool to examine DNA variation in natural populations of Populus trichocarpa. Nine different genes among individuals from 41 different populations were screened. A clear geographic pattern of the population structure of $P$. trichocarpa was established (Gilchrist et al. 2006b).

Other modifications of the TILLING strategy

An interesting modification of the TILLING method, called De-TILLING (Deletion TILLING), was reported by Rogers et al. (2009). This method expands the spectrum of available reverse genetics molecular tools for the functional characterisation of genes. In contrast to TILLING, which provides an efficient method for the identification of mainly single base pair mutations from which only approximately $5 \%$ will be null mutations, De-TILLING overcomes this shortage and exclusively detects knockout mutations. The first report in which agarose gel electrophoresis was used for deletion detection in a fast neutron treated population of Arabidopsis used the Delete-a-gene ${ }^{\circledR}$ approach ( $\mathrm{Li}$ et al. 2002). This approach is based on suppressing the amplification from wild-type sequences in order to identify specific deletion alleles in a large population of plants. Twenty-five loci were screened for deletion mutations in a population containing a total of 51,840 lines. Deletion mutants were identified at a rate of $84 \%$, which indicates that Delete-agene ${ }^{\circledR}$ can be used very effectively to knockout target genes. In crop plants, deleting unwanted genes can also be used to create improved cultivars.

Physical mutagenesis with fast neutrons has also been applied in a large population of $156,000 \mathrm{M}$. truncatula plants for De-TILLING. This population was structured and 13 super-pools were created, each representing 12,000 $\mathrm{M}_{2}$ plants. A large population size in De-TILLING is compensated by a high level of pooling. A sensitive PCR-based detection was used in order to discover null mutation in targeted genes. The screening of 14 genes in this population using five targets per gene led to the identification of mutants at a rate of $29 \%$. The screening was carried out using an average target size of $2.3 \mathrm{~kb}$ and the identified deletions removed from $18 \%$ to $68 \%$ of the target regions. Another example of using this platform for the detection of deletion in homoeologous genes in wheat was reported by Fitzgerald et al. (2010). Other physical mutagens like heavy ion irradiation (HII) have also been employed for the creation of a population. The TaqMan SNP detection method was used to identify homoeologous deletion mutants. This method relies on uniquely fluoro-labelled homoeologue-specific TaqMan SNP detection probes to identify the presence or absence of homoeologous copies of the gene of interest. This solution overcomes the technical difficulties in the application of TILLING to polyploidy crop species due to the independent amplification of homoeologous gene copies, which prevents the formation of heteroduplexes between these closely related sequences.

Although LI-COR-based techniques are commonly used for mutation screening, MALDI-TOF MS (matrix-assisted laser desorption/ionisation time-of-flight mass spectrometry)based assays have been reported for mutation detection in an oat TILLING population. In MALDI-TOF, samples are ionised and then relocated to the mass analyser, where they are separated according to their mass-to-charge ratio. The ions are then detected and analysed using specially developed software. However, there are few drawbacks with the current 


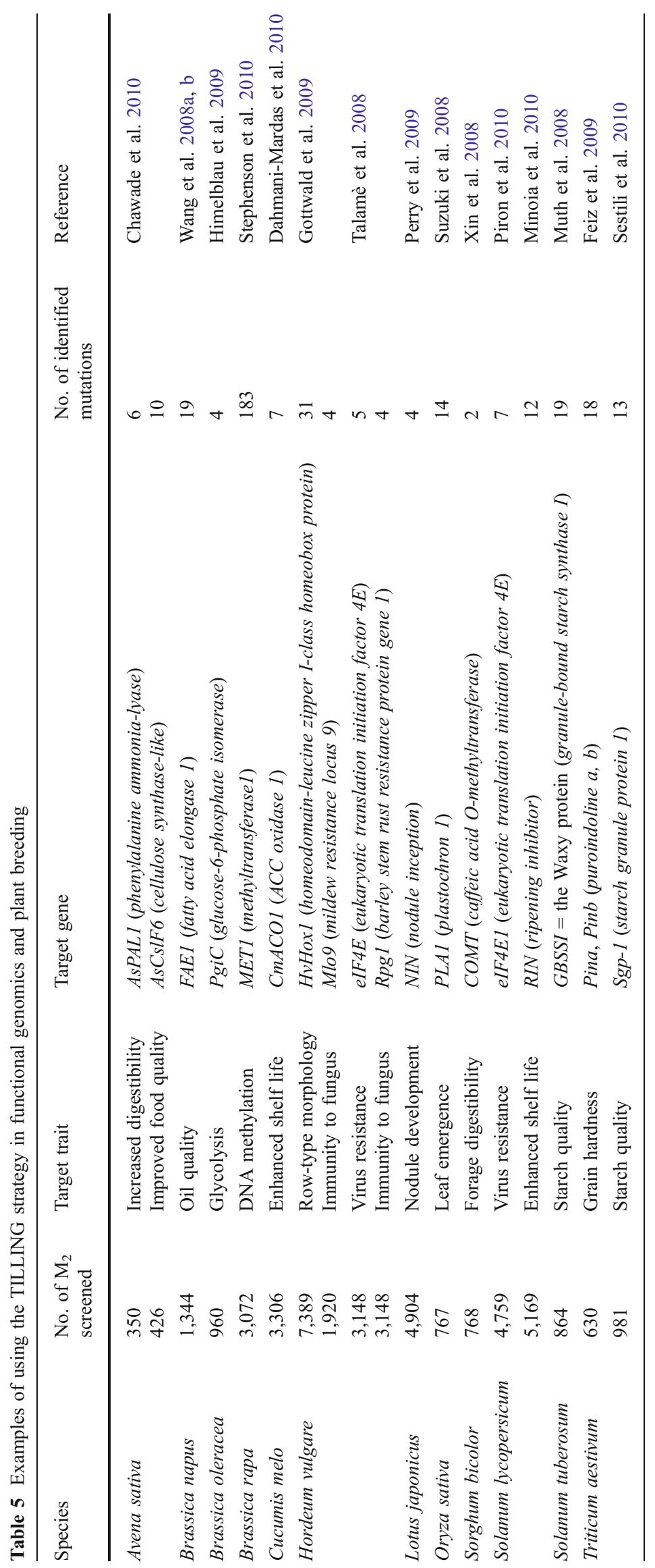


MALDI methods, e.g. its reliance on specialised equipment and software for mutation identification without automation. MALDI screening is still a low-throughput method with high costs of the chemicals needed for large-scale screening programmes (Chawade et al. 2010).

\section{New alleles identified using TILLING platforms and their importance in studying gene function and crop improvement}

Theoretically, the TILLING strategy has led to the creation and identification of a series of new alleles for any gene of interest in any plant species. However, in order to achieve this goal, certain conditions need to be fulfilled. The most important is to perform proper mutagenic treatment, which will result in a high density of mutations, as well as in a good survival rate. These two factors need to be in balance. Secondly, the $\mathrm{M}_{2}$ population needs to be large enough to make it possible to find new alleles of any of the studied genes. The creation of a mutant population for vegetatively propagated species or with a long generation time is much more challenging. For such species, Ecotilling may be the best solution, which was shown in research conducted on Musa (Till et al. 2010). Finally, it should be possible to detect any allelic series causing different changes in a coded protein for any gene and to use it to study gene function. The newly identified alleles could also be used as valuable resources in crop improvement. To date, there have been many successful examples of both approaches (Table 5). Perry et al. (2009) identified a large allelic series for 12 genes known to be essential for nodule development in $L$. japonicus. A total population of $4,904 \mathrm{M}_{2}$ plants was screened and 97 mutant alleles were detected. All possible types of mutation were identified: silent alleles that caused no change in amino acid, changes in splice sites and missense to nonsense types. This unique data set, which combines genotypic and phenotypic information, is an excellent tool for structure-function studies. Among the mutants identified, 19 alleles did not have an effect on gene function and 78 influenced the phenotype, including lines where nodulation deficiency was observed. Another investigated trait was spike morphology (Gottwald et al. 2009). A TILLING population in barley was created using the tworowed malting cultivar 'Barke'. Thirty-one mutations were identified by screening a 1,270-bp fragment of the homeodomain leucine zipper (HD-ZIP) gene HvHoxl in $7,348 \mathrm{M}_{2}$ lines. Three of the newly identified mutants exhibited either a six-rowed or an intermedium-spike phenotype, and these mutations constituted a direct link between the gene and the phenotype. Reverse genetic screening of mutagenised populations could be also used as a molecular tool for crop improvement. Enhanced shelf life was the goal for research in Cucumis melo (DahmaniMardas et al. 2010). TILLING screening in melons were performed for 4,032 $\mathrm{M}_{2}$ plants and 11 genes related to fruit quality were chosen. In total, they identified and confirmed by sequencing 134 induced mutations in an 18.3-kb total length of tilled amplicons. A detailed investigation was performed for CmACO1-ACC oxidase 1, the enzyme that catalyses the last step of ethylene biosynthesis and is connected with the shelf life of fruit. One mutation out of the seven detected in this gene, G194D, occurred in a highly conserved amino acid position and an assumption was made using crystallographic analysis that it affects the enzymatic activity. A phenotypic analysis confirmed this assumption that the mutant showed a significant delay in ripening and yellowing, with improved shelf life. Among the broad range of genes that encode traits that are of great interest to breeders, key genes in the lignin and $\beta$-glucan biosynthetic pathways were chosen in A. sativa (Chawade et al. 2010). Currently, oats are mainly used as feed for animals. A lower lignin content will increase grain digestibility, which, in turn, will increase the feeding value of the crop. However, oats rich in $\beta$-glucan have properties that are beneficial to the health of humans, such as those that improve digestion and help to lower cholesterol. Therefore, $\beta$-glucans are becoming very important food ingredients; hence, there is much more interest in oats as a food for humans. In an oat cv. 'Belinda' TILLING population, six different mutations in the phenylalanine ammonia-lyase (AsPAL1), which is a key gene in lignin biosynthesis, and ten different mutations in the cellulose synthase-like (AsCslF6) $\beta$-glucan biosynthesis gene were detected. Among them, $50 \%$ of the newly identified alleles in each analysed gene led to an amino acid change. Only a bioinformatic analysis of the identified mutation was carried out. Based on the SIFT and PSSM scores, it is more likely that mutations detected in the AsPAL1 gene rather than in the AsCslF6 gene may cause any phenotypic changes. However, this assumption needs to be proved by phenotypic tests. The alleles generated by the TILLING method might be used as new resources in the improvement of oats.

Open Access This article is distributed under the terms of the Creative Commons Attribution Noncommercial License which permits any noncommercial use, distribution, and reproduction in any medium, provided the original author(s) and source are credited.

\section{References}

Achaz G, Netter P, Coissac E (2001) Study of intrachromosomal duplications among the eukaryote genomes. Mol Biol Evol 18:2280-2288

Alonso JM, Ecker JR (2006) Moving forward in reverse: genetic technologies to enable genome-wide phenomic screens in Arabidopsis. Nat Rev Genet 7:524-536 
Alonso JM, Stepanova AN, Leisse TJ, Kim CJ, Chen H, Shinn P, Stevenson DK, Zimmerman J, Barajas P, Cheuk R, Gadrinab C, Heller C, Jeske A, Koesema E, Meyers CC, Parker H, Prednis L, Ansari Y, Choy N, Deen H, Geralt M, Hazari N, Hom E, Karnes M, Mulholland C, Ndubaku R, Schmidt I, Guzman P, AguilarHenonin L, Schmid M, Weigel D, Carter DE, Marchand T, Risseeuw E, Brogden D, Zeko A, Crosby WL, Berry CC, Ecker JR (2003) Genome-wide insertional mutagenesis of Arabidopsis thaliana. Science 301:653-657

Bolle C, Schneider A, Leister D (2011) Perspectives on systematic analyses of gene function in Arabidopsis thaliana: new tools, topics and trends. Curr Genomics 12(1):1-14

Boutros M, Ahringer J (2008) The art and design of genetic screens: RNA interference. Nat Rev Genet 9:554-566

Bush SM, Krysan PJ (2010) iTILLING: a personalized approach to the identification of induced mutations in Arabidopsis. Plant Physiol 154:25-35

Caldwell DG, McCallum N, Shaw P, Muehlbauer GJ, Marshall DF, Waugh R (2004) A structured mutant population for forward and reverse genetics in barley (Hordeum vulgare L.). Plant $\mathrm{J}$ 40:143-150

Chawade A, Sikora P, Bräutigam M, Larsson M, Vivekanand V, Nakash MA, Chen T, Olsson O (2010) Development and characterization of an oat TILLING-population and identification of mutations in lignin and $\beta$-glucan biosynthesis genes. BMC Plant Biol 10:86

Clark KA, Krysan PJ (2007) Protocol: an improved high-throughput method for generating tissue samples in 96-well format for plant genotyping (Ice-Cap 2.0). Plant Methods 3:8

Coassin S, Brandstätter A, Kronenberg F (2008) An optimized procedure for the design and evaluation of Ecotilling assays. BMC Genomics 9:510

Colbert T, Till BJ, Tompa R, Reynolds S, Steine MN, Yeung AT, McCallum CM, Comai L, Henikoff S (2001) High-throughput screening for induced point mutations. Plant Physiol 126:480-484

Comai L, Young K, Till BJ, Reynolds SH, Greene EA, Codomo CA, Enns LC, Johnson JE, Burtner C, Odden AR, Henikoff S (2004) Efficient discovery of DNA polymorphisms in natural populations by Ecotilling. Plant J 37:778-786

Cooper JL, Till BJ, Laport RG, Darlow MC, Kleffner JM, Jamai A, El-Mellouki T, Liu S, Ritchie R, Nielsen N, Bilyeu KD, Meksem K, Comai L, Henikoff S (2008) TILLING to detect induced mutations in soybean. BMC Plant Biol 8:9

Cross MJ, Waters DLE, Lee LS, Henry RJ (2008) Endonucleolytic mutation analysis by internal labeling (EMAIL). Electrophoresis 29:1291-1301

Dahmani-Mardas F, Troadec C, Boualem A, Lévêque S, Alsadon AA, Aldoss AA, Dogimont C, Bendahmane A (2010) Engineering melon plants with improved fruit shelf life using the TILLING Approach. PLoS ONE 5(12):e15776

Dalmais M, Schmidt J, Le Signor C, Moussy F, Burstin J, Savois V, Aubert G, Brunaud V, de Oliveira Y, Guichard C, Thompson R, Bendahmane A (2008) UTILLdb, a Pisum sativum in silico forward and reverse genetics tool. Genome Biol 9:R43

Deschamps S, Campbell MA (2010) Utilization of next-generation sequencing platforms in plant genomics and genetic variant discovery. Mol Breeding 25:553-570

Dong C, Dalton-Morgan J, Vincent K, Sharp P (2009) A modified TILLING method for wheat breeding. Plant Gen 2:39-47

Elias R, Till BJ, Mba C, Al-Safadi B (2009) Optimizing TILLING and Ecotilling techniques for potato (Solanum tuberosum L). BMC Res Notes 2:141

Feiz L, Martin JM, Giroux MJ (2009) Creation and functional analysis of new Puroindoline alleles in Triticum aestivum. Theor Appl Genet 118:247-257
Fitzgerald TL, Kazan K, Li Z, Morell MK, Manners JM (2010) A high-throughput method for the detection of homologous gene deletions in hexaploid wheat. BMC Plant Biol 10:264

Gady ALF, Hermans FWK, Van de Wal MHBJ, van Loo EN, Visser RGF, Bachem CWB (2009) Implementation of two high throughput techniques in a novel application: detecting point mutations in large EMS mutated plant populations. Plant Methods 5:13

Garvin MR, Gharrett AJ (2007) Deco-TILLING: an inexpensive method for single nucleotide polymorphism discovery that reduces ascertainment bias. Mol Ecol Notes 7:735-746

Geourjon C, Deléage G (1995) SOPMA: significant improvements in protein secondary structure prediction by consensus prediction from multiple alignments. Comput Appl Biosci 11(6):681-684

Gilchrist EJ, Haughn GW (2005) TILLING without a plough: a new method with applications for reverse genetics. Curr Opin Plant Biol 8:211-215

Gilchrist EJ, O'Neil NJ, Rose AM, Zetka MC, Haughn GW (2006a) TILLING is an effective reverse genetics technique for Caenorhabditis elegans. BMC Genomics 7:262

Gilchrist EJ, Haughn GW, Ying CC, Otto SP, Zhuang J, Cheung D, Hamberger B, Aboutorabi F, Kalynyak T, Johnson L, Bohlmann J, Ellis BE, Douglas CJ, Cronk QCB (2006b) Use of Ecotilling as an efficient SNP discovery tool to survey genetic variation in wild populations of Populus trichocarpa. Mol Ecol 15:1367-1378

Gottwald S, Bauer P, Komatsuda T, Lundqvist U, Stein N (2009) TILLING in the two-rowed barley cultivar 'Barke' reveals preferred sites of functional diversity in the gene HvHoxl. BMC Res Notes 2:258

Greene EA, Codomo CA, Taylor NE, Henikoff JG, Till BJ, Reynolds SH, Enns LC, Burtner C, Johnson JE, Odden AR, Comai L, Henikoff S (2003) Spectrum of chemically induced mutations from a large-scale reverse-genetic screen in Arabdiopsis. Genetics 164:731-740

Gruszka D, Szarejko I, Maluszynski M (2011) Sodium azide as a mutagen. In: Plant mutation breeding and biotechnology, pp 159 166 (in press)

Guénet JL (2004) Chemical mutagenesis of the mouse genome: an overview. Genetica 122:9-24

Henikoff S, Comai L (2003) Single-nucleotide mutations for plant functional genomics. Annu Rev Plant Biol 54:375-401

Himelblau E, Gilchrist EJ, Buono K, Bizzell C, Mentzer L, Vogelzang R, Osborn T, Amasino RM, Parkin IA, Haughn GW (2009) Forward and reverse genetics of rapid-cycling Brassica oleracea. Theor Appl Genet 118:953-961

Hirochika H (2010) Insertional mutagenesis with Tos 17 for functional analysis of rice genes. Breeding Sci 60:486-492

Ibiza VP, Cañizares J, Nuez F (2010) EcoTILLING in Capsicum species: searching for new virus resistances. BMC Genomics 11:631

Ishikawa T, Kamei Y, Otozai S, Kim J, Sato A, Kuwahara Y, Tanaka M, Deguchi T, Inohara H, Tsujimura T, Todo T (2010) Highresolution melting curve analysis for rapid detection of mutations in a Medaka TILLING library. BMC Mol Biol 11:70

Jander G, Baerson SR, Hudak JA, Gonzalez KA, Gruys KJ, Last RL (2003) Ethylmethanesulfonate saturation mutagenesis in Arabidopsis to determine frequency of herbicide resistance. Plant Physiol 131:139-146

Kadaru SB, Yadav AS, Fjellstrom RG, Oard JH (2006) Alternative Ecotilling protocol for rapid, cost-effective single-nucleotide polymorphism discovery and genotyping in rice (Oryza sativa L.). Plant Mol Biol Rep 24:3-22

Kapustin Y, Souvorov A, Tatusova T, Lipman D (2008) Splign: algorithms for computing spliced alignments with identification of paralogs. Biol Direct 3:20-33

Keller B, Feuillet C, Yahiaoui N (2005) Map-based isolation of disease resistance genes from bread wheat: cloning in a supersize genome. Genet Res 85:93-100 
Komatsuda T, Pourkheirandish M, He C, Azhaguvel P, Kanamori H, Perovic D, Stein N, Graner A, Wicker T, Tagiri A, Lundqvist U, Fujimura T, Matsuoka M, Matsumoto T, Yano M (2007) Six-rowed barley originated from a mutation in a homeodomain-leucine zipper I-class homeobox gene. Proc Natl Acad Sci 104:1424-1429

Krattinger SG, Wicker T, Keller B (2009) Map-based cloning of genes in Triticeae (wheat and barley). In: Muehlbauer G, Feuillet C (eds) Genetics and genomics of the triticeae, plant genetics and genomics: crops and models. Springer Science+Business Media, LLC, pp 337-357

Krysan P (2004) Ice-Cap. A high-throughput method for capturing plant tissue samples for genotype analysis. Plant Physiol 135:1162-1169

Kyte J, Doolittle RF (1982) A simple method for displaying the hydropathic character of a protein. J Mol Biol 157:105-132

Lababidi S, Mejlhede N, Rasmussen SK, Backes G, Al-Said W, Baum M, Jahoor A (2009) Identification of barley mutants in the cultivar 'Lux' at the Dhn loci through TILLING. Plant Breeding 128:332-336

Le Signor C, Savois V, Aubert G, Verdier J, Nicolas M, Pagny G, Moussy F, Sanchez M, Baker D, Clarke J, Thompson R (2009) Optimizing TILLING populations for reverse genetics in Medicago truncatula. Plant Biotechnol J 7:430-441

Li X, Song Y, Century K, Straight S, Ronald P, Dong X, Lassner M, Zhang Y (2001) A fast neutron deletion mutagenesis-based reverse genetics system for plants. Plant J 27:235-242

Li X, Lassner M, Zhang Y (2002) Deleteagene: a fast neutron deletion mutagenesis-based gene knockout system for plants. Comp Funct Genomics 3(2):158-160

Maluszynski M, Szarejko I, Maluszynska J (2003) Mutation techniques. In: Thomas B, Murphy DJ, Murray BG (eds) Encyclopedia of applied plant sciences. Elsevier Academic Press, San Diego, pp 186-201

Martín B, Ramiro M, Martínez-Zapater JM, Alonso-Blanco C (2009) A high-density collection of EMS-induced mutations for TILLING in Landsberg erecta genetic background of Arabidopsis. BMC Plant Biol 9:147

McCallum CM, Comai L, Greene EA, Henikoff S (2000) Targeting Induced Local Lesions IN Genomes (TILLING) for plant functional genomics. Plant Physiol 123:439-442

Mejlhede N, Kyjovska Z, Backes G, Burhenne K, Rasmussen SK, Jahoor A (2006) EcoTILLING for the identification of allelic variation in the powdery mildew resistance genes mlo and Mla of barley. Plant Breeding 125:461-467

Menda N, Semel Y, Peled D, Eshed Y, Zamir D (2004) In silico screening of a saturated mutation library of tomato. Plant J 38:861-872

Milburn D, Laskowski RA, Thornton JM (1998) Sequences annotated by structure: a tool to facilitate the use of structural information in sequence analysis. Protein Eng 11(10):855-859

Minoia S, Petrozza A, D’Onofrio O, Piron F, Mosca G, Sozio G, Cellini F, Bendahmane A, Carriero F (2010) A new mutant genetic resource for tomato crop improvement by TILLING technology. BMC Res Notes 3:69

Mochida K, Shinozaki K (2010) Genomics and bioinformatics resources for crop improvement. Plant Cell Physiol 51(4):497-523

Muth J, Hartje S, Twyman RM, Hofferbert HR, Tacke E, Prüfer D (2008) Precision breeding for novel starch variants in potato. Plant Biotechnol J 6:576-584

Nieto C, Piron F, Dalmais M, Marco CF, Moriones E, GómezGuillamón ML, Truniger V, Gómez P, Garcia-Mas J, Aranda MA, Bendahmane A (2007) EcoTILLING for the identification of allelic variants of melon eIF4E, a factor that controls virus susceptibility. BMC Plant Biol 7:34

Nolan PM, Peters J, Vizor L, Strivens M, Washbourne R, Hough T, Wells C, Glenister P, Thornton C, Martin J, Fisher E, Rogers D, Hagan J, Reavill C, Gray I, Wood J, Spurr N, Browne M, Rastan
S, Hunter J, Brown SD (2000) Implementation of a large-scale ENU mutagenesis program: towards increasing the mouse mutant resource. Mamm Genome 11:500-506

Oleykowski CA, Bronson Mullins CR, Godwin AK, Yeung AT (1998) Mutation detection using a novel plant endonuclease. Nucleic Acids Res 26:4597-4602

Østergaard L, Yanofsky MF (2004) Establishing gene function by mutagenesis in Arabidopsis thaliana. Plant J 39:682-696

Perry JA, Wang TL, Welham TJ, Gardner S, Pike JM, Yoshida S, Parniske M (2003) A TILLING reverse genetics tool and a webaccessible collection of mutants of the legume Lotus japonicus. Plant Physiol 131:866-871

Perry J, Brachmann A, Welham T, Binder A, Charpentier M, Groth M, Haage K, Markmann K, Wang TL, Parniske M (2009) TILLING in Lotus japonicus identified large allelic series for symbiosis genes and revealed a bias in functionally defective ethyl methanesulfonate alleles toward glycine replacements. Plant Physiol 151:1281-1291

Piron F, Nicolaï M, Minoïa S, Piednoir E, Moretti A, Salgues A, Zamir D, Caranta C, Bendahmane A (2010) An induced mutation in tomato eIF4E leads to immunity to two potyviruses. PLoS ONE 5(6): 11313

Ramos ML, Huntley JJ, Maleki SJ, Ozias-Akins P (2009) Identification and characterization of a hypoallergenic ortholog of $\mathrm{Ara}$ h 2.01. Plant Mol Biol 69:325-335

Rigola D, van Oeveren J, Janssen A, Bonné A, Schneiders H, van der Poel HJA, van Orsouw NJ, Hogers RCJ, de Both MTJ, van Eijk MJT (2009) High-throughput detection of induced mutations and natural variation using KeyPoint ${ }^{\mathrm{TM}}$ Technology. PloS ONE 4(3): e4761

Rogers C, Wen J, Chen R, Oldroyd G (2009) Deletion-based reverse genetics in Medicago truncatula. Plant Physiol 151:10771086

Sadiq MF, Owais WM (2000) Mutagenicity of sodium azide and its metabolite azidoalanine in Drosophila melanogaster. Mutat Res 469:253-257

Sato Y, Shirasawa K, Takahashi Y, Nishimura M, Nishio T (2006) Mutant selection from progeny of gamma-ray-irradiated rice by DNA heteroduplex cleavage using Brassica petiole extract. Breed Sci 56:179-183

Sestili F, Botticella E, Bedo Z, Philips A, Lafiandra D (2010) Production of novel allelic variation for genes involved in starch biosynthesis through mutagenesis. Mol Breeding 25:145-154

Slade AJ, Fuerstenberg SI, Loeffler D, Steine MN, Facciotti D (2005) A reverse genetic, nontransgenic approach to wheat crop improvement by TILLING. Nat Biotechnol 23:75-81

Small I (2007) RNAi for revealing and engineering plant gene functions. Curr Opin Biotechnol 18:148-153

Smits BM, Mudde J, Plasterk RH, Cuppen E (2004) Target-selected mutagenesis of the rat. Genomics 83:332-334

Sreelakshmi Y, Gupta S, Bodanapu R, Chauhan VS, Hanjabam M, Thomas S, Mohan V, Sharma S, Srinivasan R, Sharma R (2010) NEATTILL: A simplified procedure for nucleic acid extraction from arrayed tissue for TILLING and other high-throughput reverse genetic applications. Plant Methods 6:3

Stamm S, Riethoven JJ, Le Texier V, Gopalakrishnan C, Kumanduri V, Tang Y, Barbosa-Morais NL, Thanaraj TA (2006) ASD: a bioinformatics resource on alternative splicing. Nucleic Acids Res 34: D46-D55

Stephenson P, Baker D, Girin T, Perez A, Amoah S, King GJ, Østergaard L (2010) A rich TILLING resource for studying gene function in Brassica rapa. BMC Plant Biol 10:62

Suzuki T, Eiguchi M, Kumamaru T, Satoh H, Matsusaka H, Moriguchi K, Nagato Y, Kurata N (2008) MNU-induced mutant pools and high performance TILLING enable finding of any gene mutation in rice. Mol Genet Genomics 279:213-223 
Talamè V, Bovina R, Sanguineti MC, Tuberosa R, Lundqvist U, Salvi S (2008) TILLMore, a resource for the discovery of chemically induced mutants in barley. Plant Biotechnol J 6:477-485

Taylor NE, Greene EA (2003) PARSESNP: a tool for the analysis of nucleotide polymorphisms. Nucleic Acids Res 31(13):3808-3811

Thanaraj TA, Stamm S, Clark F, Riethoven JJ, Le Texier V, Muilu J (2004) ASD: the Alternative Splicing Database. Nucleic Acids Res 32:D64-D69

Till BJ, Reynolds SH, Greene EA, Codomo CA, Enns LC, Johnson JE, Burtner C, Odden AR, Young K, Taylor NE, Henikoff JG, Comai L, Henikoff S (2003) Large-scale discovery of induced point mutations with high-throughput TILLING. Genome Res 13:524-530

Till BJ, Reynolds SH, Weil C, Springer N, Burtner C, Young K, Bowers E, Codomo CA, Enns LC, Odden AR, Greene EA, Comai L, Henikoff S (2004a) Discovery of induced point mutations in maize genes by TILLING. BMC Plant Biol 4:12

Till BJ, Burtner C, Comai L, Henikoff S (2004b) Mismatch cleavage by single-strand specific nucleases. Nucleic Acids Res 32:2632-2641

Till BJ, Zerr T, Comai L, Henikoff S (2006a) A protocol for TILLING and Ecotilling in plants and animals. Nat Protoc 1:2465-2477

Till BJ, Zerr T, Bowers E, Greene EA, Comai L, Henikoff S (2006b) High-throughput discovery of rare human nucleotide polymorphisms by Ecotilling. Nucleic Acids Res 34(13):e99

Till BJ, Cooper J, Tai TH, Colowit P, Greene EA, Henikoff S, Comai L (2007) Discovery of chemically induced mutations in rice by TILLING. BMC Plant Biol 7:19

Till BJ, Jankowicz-Cieslak J, Sági L, Huynh OA, Utsushi H, Swennen R, Terauchi R, Mba C (2010) Discovery of nucleotide polymorphisms in the Musa gene pool by Ecotilling. Theor Appl Genet 121:1381-1389

Triques K, Sturbois B, Gallais S, Dalmais M, Chauvin S, Clepet C, Aubourg S, Rameau C, Caboche M, Bendahmane A (2007) Characterization of Arabidopsis thaliana mismatch specific endonucleases: application to mutation discovery by TILLING in pea. Plant J 51(6):1116-1125

Triques K, Piednoir E, Dalmais M, Schmidt J, Le Signor C, Sharkey M, Caboche M, Sturbois B, Bendahmane A (2008) Mutation detection using ENDO1: application to disease diagnostics in humans and TILLING and Eco-TILLING in plants. BMC Mol Biol 9:42

Uauy C, Paraiso F, Colasuonno P, Tran RK, Tsai H, Berardi S, Comai L, Dubcovsky J (2009) A modified TILLING approach to detect induced mutations in tetraploid and hexaploid wheat. BMC Plant Biol 9:115

Upadhyaya NM, Zhu Q-H, Bhat RS (2011) Transposon insertional mutagenesis in rice. In: Pereira A (ed) Plant reverse genetics, methods and protocols, methods in molecular biology. Springer Science+Business Media, LLC, pp 147-177

Vriet C, Welham T, Brachmann A, Pike M, Pike J, Perry J, Parniske M, Sato S, Tabata S, Smith AM, Wang TL (2010) A suite of Lotus japonicus starch mutants reveals both conserved and novel features of starch metabolism. Plant Physiol 154:643-655

Wang G-X, Tan M-K, Rakshit S, Saitoh H, Terauchi R, Imaizumi T, Ohsako T, Tominaga T (2007) Discovery of single-nucleotide mutations in acetolactate synthase genes by Ecotilling. Pestic Biochem Physiol 88:143-148

Wang J, Sun J, Liu D, Yang W, Wang D, Tong Y, Zhang A (2008a) Analysis of Pina and Pinb alleles in the micro-core collections of Chinese wheat germplasm by Ecotilling and identification of a novel Pinb allele. J Cereal Sci 48:836-842

Wang N, Wang Y, Tian F, King GJ, Zhang C, Long Y, Shi L, Meng J (2008b) A functional genomics resource for Brassica napus: development of an EMS mutagenized population and discovery of FAE1 point mutations by TILLING. New Phytol 180:751765

Wang N, Shi L, Tian F, Ning H, Wu X, Long Y, Meng J (2010) Assessment of FAE1 polymorphisms in three Brassica species using EcoTILLING and their association with differences in seed erucic acid contents. BMC Plant Biol 10:137

Wienholds E, van Eeden F, Kosters M, Mudde J, Plasterk RHA, Cuppen E (2003) Efficient target-selected mutagenesis in zebrafish. Genome Res 13:2700-2707

Winkler S, Schwabedissen A, Backasch D, Bökel C, Seidel C, Bönisch S, Fürthauer M, Kuhrs A, Cobreros L, Brand M, González-Gaitán M (2005) Target-selected mutant screen by TILLING in Drosophila. Genome Res 15:718-723

Xin Z, Wang ML, Barkley NA, Burow G, Franks C, Pederson G, Burke J (2008) Applying genotyping (TILLING) and phenotyping analyses to elucidate gene function in a chemically induced sorghum mutant population. BMC Plant Biol 8:103

Zhang JY, Lu Y, Yuan Y, Zhang X, Geng J, Chen Y, Cloutier S, McVetty PBE, Li G (2009) Map-based cloning and characterization of a gene controlling hairiness and seed coat color traits in Brassica rapa. Plant Mol Biol 69:553-563 